Conditions prevailing at the time EPS was founded in 1965-68 are not directly responsible for its birth, but the idea of a fully European society of individual physicists was neverthless well timed.

\title{
Europe in 1965-1968
}

The European Physical Society came to life twenty years after World War II, between 1965 (with the first proposal of Gilberto Bernardini) and 1968 (the official constitution in Geneva). The Society aimed to establish or improve scientific links, not between governmental bodies, but between individual scientists belonging to all European nations. The boldness of the vision underlying Bernardini's proposal can only be understood if we remember that these nations were at the time sharply split into two political and military blocks, and that scientific activities were deeply related to the arms race and to an increasingly competitive industrial perspective. Morever, the image of science itself as a purely cultural activity was being questioned by professionals historians and philosophers, and by international political movements firmly rooted in the universities. The almost unanimous acceptance of the proposal and the successful birth of the Society show that European physicists were willing to overcome all these difficulties in order to further an international and truely scientific cooperation. A short historical analysis of those years helps understand better some of the unique features of the birth of EPS.

\section{The East-West Blocks}

After the Yalta peace talks (1945) and despite the efforts connected with the establishment of the United Nations (1945), the North Atlantic Treaty Organization (1949) and the Warsaw Pact (1955) confronted each other in the "cold war". Not so cold were the explosions of atomic bombs in 1949 by the former USSR, in 1952 by Great Britain, and in 1960 by France, and of hydrogen bombs (by the USA in 1952, the USSR in 1953. Great Britain in 1957, and France in 1968). Relevant also were the launches of the first artificial satellites (by the USSR in 1957, the USA in 1958, France in 1965, and Great Britain in 1971), the space race from the first orbital trip (Yuri Gagarin, 1961) to the landing on the moon (Niel Armstrong in 1969).

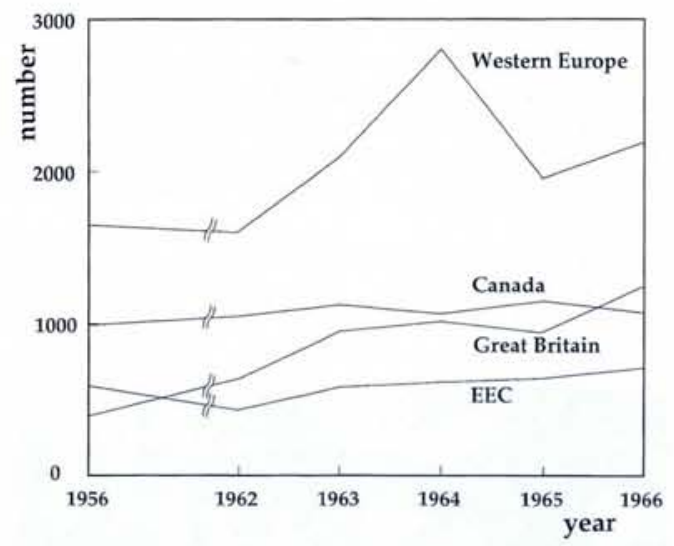

The number of scientists and engineers emigrating to the United States based on the last country of residence. Taken from The Brain Drain into the United States of Scientists, Engineers and Physicians (US Govt. Printing Office, Washington, 1967).

\author{
F. Bevilacqua, E. Giannetto,, G. Tagliaferri ${ }^{+}$ \\ ${ }^{*}$ University of Pavia \\ ${ }^{+}$University of Milan
}

Confrontation was not confined to a single region of the planet (the Korean War of 1950-53; military regimes in Latin America; the Afghanistan invasion in 1979), but it deeply influenced Europe with the Prague coup (1948), repression in Poland and Hungary (1956), the building of the Berlin wall (1961), the military coup in Greece (1967-74), the invasion of Czechoslovakia (1968), and eventually the military regime in Poland (1981).

The political situation sometimes seemed to offer hope for improvement: the rejection of Stalinism by the 20th Congress of the Communist Party of the former Soviet Union (1956), the election of John F. Kennedy (1961) as the President of the United States, the new atmosphere of "dialogue" at the 2nd Vatican Council of the Roman Catholic Church (Pope John XXIII). But hopes never lasted very long: the Cuban missile crisis (1962), the assassination of Kennedy (1963), and the destitution of Kruschev (1964) reinforced the cold war and the arms race, and 1965 saw an escalation on the war in Vietnam (1965-75).

Western European nations at the same time were undergoing the not always painless process of decolonisation, and started to look with more interest to closer links between each other (the European Coal and Steel Community, 1951; formation of the Organization for European Economic Cooperation; European Economic Community, 1957, with Great Britain, Denmark and Ireland joining in 1973).

Economic development, stimulated at the beginning by the Marshall Plan (1947), and internal political changes (socialists in government in Italy in 1965, the great coalition in the Federal Republic of Germany in 1966) allowed attempts at a different approaches towards the eastern block, the most relevant of which was the beginning of Ostpolitik by Willy Brandt, the Federal Republic's Prime Minister, in 1969.

\section{The Growing Rôle of Science}

Physicists sometimes had first-hand experience of the effects of political and military confrontation (Oppenheimer during MacCarthyism in the USA in 1953) and some reacted to military research (the Pugwash movement with the Russell-Einstein Manifesto in 1955; the 14th Pugwash meeting held in Venice in April 1965 with Bernardini as the chairman; the United Nations designating 1965 to be the Year of International Cooperation). More generally, physicists needed to become acquainted with the completely new rôle of science in modern society. It became evident that science was now a primary element of innovation, industrial production and military power. State and science came closer together. After the Manhattan atom bomb project and wartime research into radar, "big science" implied large-scale cooperation and very large budgets. Despite national and private

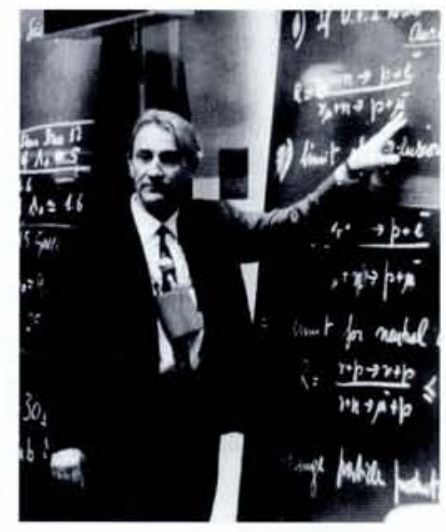

Professor Gilberto Bernardini, the first EPS President, answering questions during a seminar at CERN in November 1964 on neutrino experiments.

The cover page of the proceedings, edited by L.A. Radicati and A. Zichichi, of the Meeting on European Collaboration in Physics held at Pisa on 16-17 April 1966.

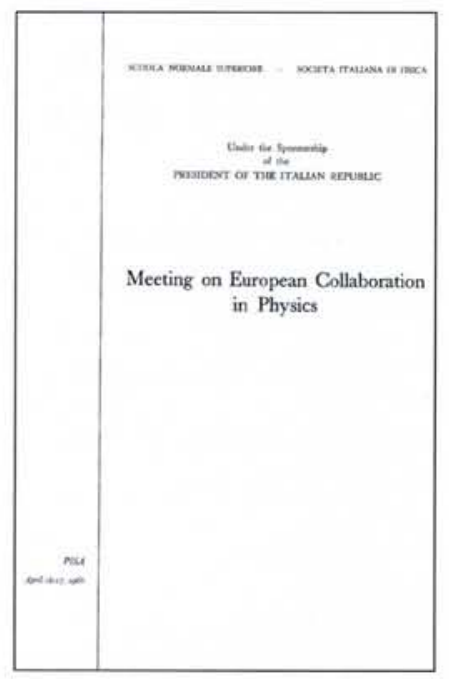




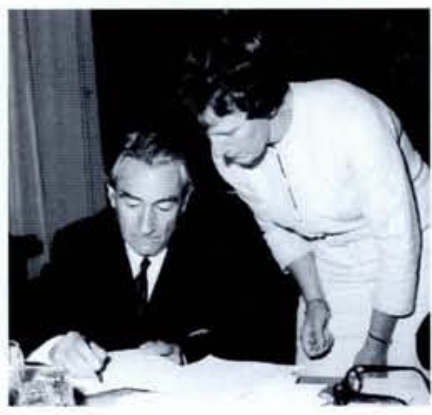

G. Bernardini enrolling as an EPS member at the Plenary Meeting at CERN on 26 September 1968. Bernardini joined CERN in 1957 after spending 6 years as a research professor at the University of Illinois, USA. He became a member of CERN's Directorate for research in 1961, and left in 1963 to take up an appointment at the University of Rome for a short period before becoming the Director of the Scuola Normale Superiore in Pisa.
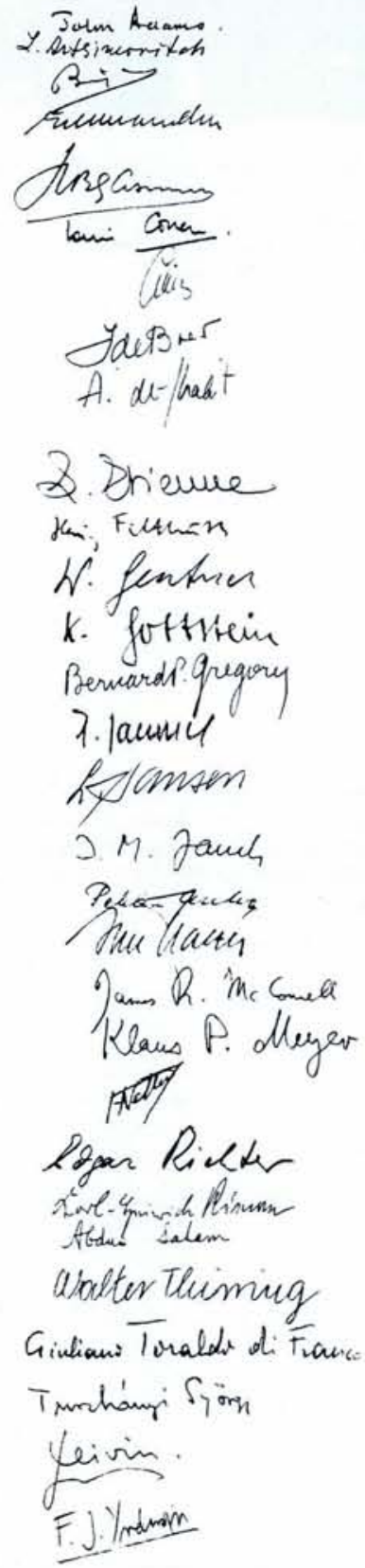

commitments to research and development, supranational organizations and projects became necessary. Many took off in the 1950's and 1960's in Europe: CERN, 1953; European Organization for the Protection of the Planet, 1953; Joint Institute for Nuclear Research, JINR, 1956; European Nuclear Energy Agency, 1957; European Society for the Chemical Treatment of Irradiated Combustibles, EUROCHEMIC, 1957; European Atomic Energy Community, EURATOM, 1957; European Space Research Organization, 1962; European Launcher Development Organization, 1962. But at the time, the only organizations of physicists based on individual (as opposed to government) participation and open to every nationality were the Groupement Ampère, the International Union of Pure and Applied Physics (IUPAP), and the International Council of Scientific Unions (ICSU) which had concluded a cooperation agreement with the United Nations Economic, Scientific and Cultural Organization (UNESCO) in 1946.

Competition to recruit the best scientists became fiercer, leading to tensions among countries in the Western block. The United States lifted immigration quotas in 1965, and particularly welcomed scientists; Britain was the country most affected by the emigration of intellectuals. Jean-Jacques Servan-Schreiber's book Le Défi Américain became a popular theme for debate. In 1966, Harold Wilson, the British Prime Minister, raised the question of a joint European effort, as did the French minister of research the same year at the European Parliament in Strasbourg.

The Image of the Physical Sciences

Public understanding of physics and of its place in modern culture was undergoing profound changes in the years the EPS was coming to life. Immediately after the explosion of the atomic bomb, James Conant at Harvard stressed the importance of improving science education to allow citizens to have a better understanding and a more democratic control of science policies. Dissatisfaction with the results of scientific education was widespread. After the launch of the Soviet Sputnik in 1957, new projects to improve physics teaching were financed, mostly in the USA (Harvard University's Project Physics Course and Feynman's Lectures in Physics are wellknown examples). In 1967, the Council of Europe promoted the survey The Teaching of Physics at University Level aimed at a improving cooperation in the field: The results were (and remain) fairly unencouraging; recurrent are claims stressing the lack of good results in the teaching of physical concepts and theories, and the failure of educated citizens to meet the challenge of continuous scientific and technical innovation.

University students were also dissatisfied in the 1960's with a scientific education overly oriented toward technical results and presented in a way that implied no value. Their worldwide protest started in 1965, but gathered momentum in 1968. Concern over the rights of free speech, criticism of educational approaches, and rebellion against economic and political establishments had, in many countries, influences well beyond the universities' borders. The reforms that followed did not solve the problems of scientific education. Indeed, educational research shows that the concerns are the same in the early 1990's as in the early 1960's.

But the scenario in which EPS was born has another element that should be highlighted, namely the changing image of physics among historians, philosophers and sociologists of science. The prevailing interpretation of science after World War II was connected with the analysis of the 1930's developed in the so-called Vienna and Berlin circles (logical positivism). The distinct separation between scientific and non-scientific elements was criticised by Albert Einstein, among others, in a famous letter of 1953. In the late-1950's and early 1960's, physicists turned historians and philosophers (Holton, Kuhn, Hanson) offered a new view of physics: historical, philosophical, psychological, and social elements are essential aspects of scientific activity and of its results. Following this view, the "two cultures" distinction and gap does not belong to scientific research but is the result of the way we teach science. In science education a process of "normalization" of scientific activity for pedagogical purposes in fact takes place: the stress is on the justification of scientific results while the contexts of discovery and corroboration are neglected. The historians' view instead presents science as a fully human activity and rejects the cliché of the scientist working in an "ivory tower".

\section{Bernardini's Initiative}

Nowadays "collaboration" is a magic word. It could be applied to almost all aspects of human life, from economics to religion; and this seems particularly true in science, where the use of a common language and the rationality of means and purposes should make mutual understanding possible on any occasion. Aspiration to collaborate in all fields originates in the very human and common desire of life which, besides the sacred frontiers of privacy, is supposed to give the comforting feeling that our work may have tangible value and that cooperation may become a reality as soon as there is a need for it... It may be that those who this morning signed the Constitution of the European Physical Society, in spite of their appearing as very sensible people, are in fact Utopians. Being one of these people, I very much hope that this is not true..

However, there is something in the spirit of the "Founding Fathers" of this Society that may be considered as utopic, particularly these days - and this is "Europe". What in fact is Europe? Geographically, it is a conventionally defined continent. Historically, it is the cradle of the greatest civilization. It is to this very civilization that one has to refer whenever we may be accused of utopistic thinking... despite some present appearances, we still firmly believe that the deep cultural and intellectual affinities on which this civilization is based do still exist; indeed they are existing "in spite of our wars and even because of our wars"... In the existence of the cultural and moral unity of that world area which is named Europe, we firmly believe, though not as Utopia, but as a reality to which the European Physical Society is deemed to give a marginal but tangible contribution in the years to come... The new civilizations that were born on all continents have not yet been able to shape a culture which is suitable to receive the inheritance of the

The opening of the Inaugural Conference The Growth Points in Physics (Florence, 8-12 April 1969). From the left, A. Kastler, V.F. Weisskopf, P.M.S. Blackett, G.H Stafford, L. Jansen, L. Cohen, and G. Bernardini.

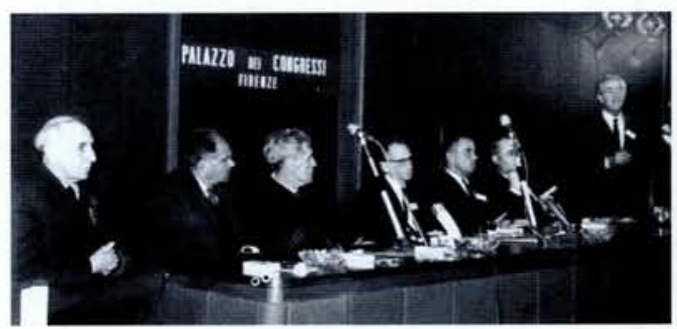




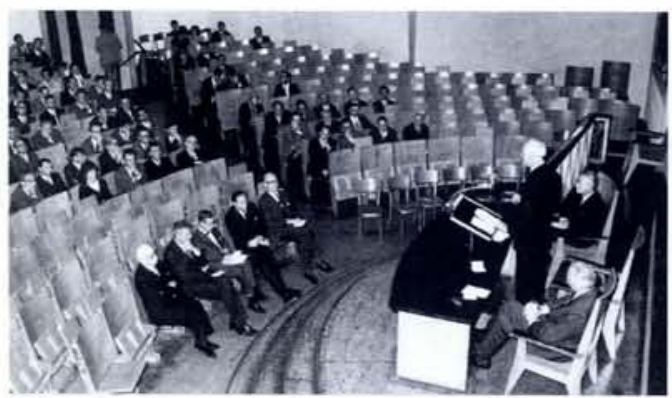

The official inauguration of the Society in the Aula Magna of the University of Geneva in the afternoon of 26 September 1968. D. van Berchem, the University's Rector, is flanked on the platform by Bernardini and by E. Valloton, the representative of the Swiss Ministry of Foreign Affairs.

humanistic culture born with the Renaissance. Technically they develop up to the highest achievements, but not equivalently on the lines of a new culture, the basis for a better mutual understanding, the origin of a peaceful world... We do believe, then, that Europe is the country that has the best chances of bringing a fundamental contribution to the creation of this new approach to the life where science will represent a new humanism for the structure of societies, as well as for the comfort of individuals. The European Physical Society, according to us, should be framed into these hopes.

These are some of the ideas presented by the Italian physicist Gilberto Bernardini at the ceremony for the foundation of the European Physical Society, in the Aula Magna of the University of Geneva, on 26 September 1968.

Bernardini had the initial idea of a European Physical Society, and he later became its first President. One of us spoke with Bernardini in October 1992, now eighty-seven years old, in a small village near Florence where he lives. With his characteristic enthusiasm, he kindly agreed to tell us something of the ideals of those days.

"At that time I had had several cultural and human experiences. I had been in the USA and I found it hard to accept the idea that in Europe there were, bound to the many laboratories and institutions, so many separate national physical societies. On the other hand, we were used to speaking English as the only language at meetings. So I thought that national languages could in practice, and with little difficulty, be superseded for cultural, intellectual and personal communication between people involved in physics research and education. CERN already existed and I spoke for the first time of the idea of a European Physical Society at the annual conference of the Italian Physical Society in November 1965. in Bologna. I remember having stressed how this European focus could be one of the very first cultural elements able to show that in Europe many languages can be accommodated, as in Italy with its different regions where many dialects are common. I said that the idea of constituting a European Physical Society, perhaps in Switzerland as it was a country with a long tradition of internationalism, was a viable idea to develop.

I remember particularly the collaboration with the German physicist Wolfgang Gentner, and with Georges-Jean Béné from France, Laurens Jansen from The Netherlands, Josef-Maria Jauch from Switzerland, and Louis Cohen from London, and with Lorette Etienne, the secretary. So conception took place in Bologna, and after several steps there was the birth.

The most relevant aspect was the presence of countries from eastern Europe. In my opinion, EPS was an invitation to unify the whole Europe. In this respect, some physicists told me that I was a strange symbiosis of intellect and romantic sentimentalism. It was very important that CERN existed, an organization whose creation had been inspired by the perspective vision of
Edoardo Amaldi, another Italian physicist; we were, in some sense, the first "Europeans". However, the formation of EPS was a general aspiration so the idea of a European society soon had a very large consensus from within the physics community."

A letter written in May 1968 by Bernardini to Frantisek Janouch of the Czechoslovak Academy of Sciences shows the importance attached to having eastern Europe present in EPS: “... Such a Society without the participation of the Socialist countries would have been an unhealthy child with no perspective for a reasonable growth. Even more, the motivations which moved the physicists in Pisa two years ago would have been deluded and frustrated..."

Bernardini's initiative was certainly widely endorsed: a brief analysis of his correspondence gives us an idea of his successful attempts to involve other physicists and the national physical societies in the constitution of EPS. By December 1967, the Steering Committee for the formation numbered 33 physicists from Britain (6), Switzerland (3), Italy (3), West Germany (3), France (2), The Netherlands (2), Denmark (2), Spain (1), Sweden (1), Austria (1), the USSR (1), Poland (1), Yugoslavia (1), Finland (1), Israel (1), and the USA (2), most of whom also represented their national physical societies. Other societies that were to participate came from Belgium, Czechoslovakia, the German Democratic Republic, Greece, and Ireland. The Steering Committee steadily grew in size over the following year, numbering just over 50 by the inauguration (when Hungary and Romania also joined). Born, Heisenberg, De Broglie, Bondi - only to recall some names - and other great physicists gave positive answers to Bernardini's invitation to form EPS. It took three years of effort from the first inspiration in 1965 to the administrative organization, first at the University of Geneva and later at the Institut Battelle.

\section{In Hindsight}

Bernardini's initiative can be understood in the framework of the Italian cultural inheritance, where physicists usually also have a humanistic background. However, the appearance of EPS cannot be understood on the basis of the work of only one person, or within the context of a single national community. It is also necessary to acknowledge the rôle of the national societies and of the post-war international physics community, and of international organizations such as CERN, where Bernardini became a member of the Directorate in 1961. Economics dictated the need for international cooperation in experimental particle physics, and this led to an outstanding European forum which certainly stimulated the EPS initiative.

Among the discussions that took place in the years EPS was being formed, two themes deserve to be remembered because they are still debated today. First, a plan to coordinate European physics journals; and second, the choice between a federation of existing national societies and a new and autonomous European society based on individual members.

Beyond the subjective positions of various individuals or groups in relation to these two themes, the EPS has, in any event, been able to realize its principal goal of giving to the existing European physics community its first institutional and organized form. By 1972, Jules Guéron, the EURATOM Director, identified EPS as "an independent association with very little financial support which contributes in an effective way to strengthening the relations between physicists, both individually and in national and divisional groups".

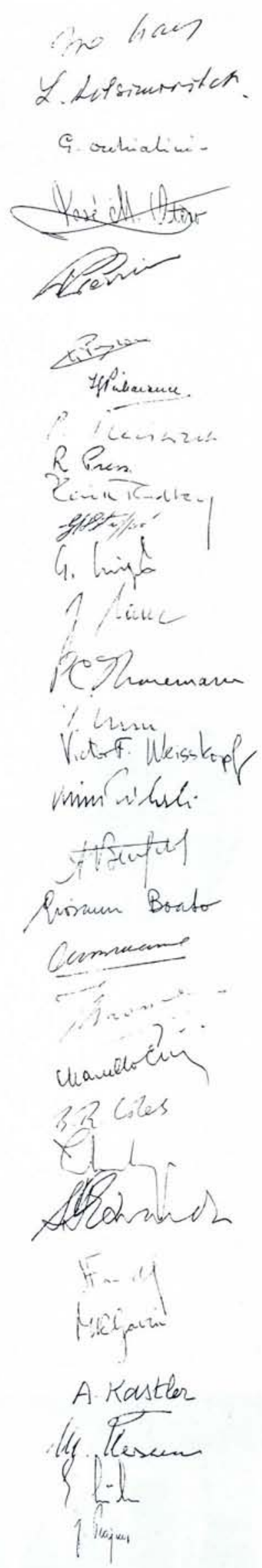

The signatures of those who enrolled as EPS members on 26 September 1968 . 